\title{
The Deeper Wounds: Living in the Trauma Zone in Jawad Al-Assadi's Baghdadi Bath and Mithal Ghazi's A Feminine Solo
}

\author{
https://doi.org/10.33806/ijaes2000.20.2.7 \\ Maysoon Taher Muhi \\ University of Baghdad, Iraq
}

\begin{abstract}
Various literary studies have investigated the psychological, social and cultural effects of traumatic events. They give voice to traumatised victims and enable them to convey and confront their traumas. However, these studies present a one-sided view, concentrating largely on the presentation of trauma in the industrial societies of the Western world. Recently, increasing attention has been devoted to identifying and depicting the forms and types of trauma that have been experienced in marginalised and neglected societies, such as the Iraqi society. Iraq has witnessed the unexpected fall of a brutal dictatorship, Western invasion and an unprecedented rise of sectarian discourses. This extreme violence has deeply affected many aspects of cultural production, particularly the rise of trauma in dramatic works of art. The present paper aims to examine two plays, namely, Jawad Al-Assadi's Baghdadi Bath and Mithal Ghazi's A Feminine Solo, using trauma theory in analysing the notions of the traumatic effect of war on survivors and Antonin Artaud's Theatre of Cruelty in explaining the issue of staging violence. This paper concludes that these plays bear witness to and expose the devastating effect of war on the identities of traumatised Iraqi characters, while at the same time, endowing them with a sense of hope to overcome their traumatised state.
\end{abstract}

Keywords: A Feminine Solo, Baghdadi Bath, Iraqi theatre, Theatre of Cruelty, Trauma

\section{Introduction}

We live in a world torn and scarred by violence. Globalisation has increased the speed and scale of conflicts and catastrophes, but violence has been integral to the human condition from our earliest origins. We should expect, therefore, to find its traces in the design of our brains and bodies no less than in the weave of our communities. Kirmayer et al. (2007: 1) in Understanding Trauma.

Throughout history, Iraq as a battlefield, witnessed periods of violence and chaos in the $20^{\text {th }}$ and $21^{\text {st }}$ centuries, which is described by Felman (2002:171) as 'centur[ies] of trauma'. Iraq has witnessed and is still facing grave danger due to political, economic and social unrest. Such events include the military revolution of 1968 that brought the dictatorship of the Arab Socialist Ba'ath Party into power and of Saddam Hussein (1968-2003), the long and brutal war with Iran (19801988), the invasion of Kuwait, the two Gulf Wars in 1991 and 2003, the 1991 uprisings, the crippling economic embargo (1991-2003), the post-2003 invasion era and finally the aggressive sectarian conflicts and ethnic tension and terrorism. These upheavals have and will continue to have drastic effects on Iraqi generations who find themselves trapped in a grey zone of a seemingly 
interminable chaos and violence that has traumatised them. To discuss the interconnection of warfare, violence and trauma, Martin Jay argues that war has become a fundamental basis of today's modern world, "structuring and sustaining our ways of existence and of socio-political and transnational intelligibility" (2003:3). Accordingly, war trauma and violence shatter individuals' self-identity and threaten their integrity.

LaCapra (2001), a prominent scholar in literary trauma studies, indicates that literature can provide insights into traumatic events, which other fields of knowledge, such as history and philosophy, cannot. Furthermore, no debate has taken place over the fact that theatre, since its beginning, holds up a truthful and salient mirror to society, reading a community and graphically revealing its political, social and economic reality. In a world of radical change, division and tension, war, violence and trauma are among the major themes presented in theatre, and the Iraqi theatre is no exception to this rule. Evidence from the theatrical sphere and production has shown that the Iraqi theatre precisely articulates how the Iraqi nation is plagued by the horror of war that delves deeply into the nation's human psyche. The Iraqi theatre reflects the formidable atrocities and complex consequences of war and the unhealed wounds that have inflicted people's lives.

This paper seeks to investigate the effects of the traumatic experiences of Iraqis through examining two Iraqi plays, that is, Jawad Al-Assadi's Baghdadi Bath (2006) and Mithal Ghazi's A Feminine Solo (2013). The analysis is based on the theory of trauma, which not only contributes to "make terrifying, alien experiences more understandable and accessible" but also presents a means of "witnessing or testifying for the history and experience of historically marginalised people" (Vickroy, 2002: 222). The expressive and emotive force of the trauma and its effect on the audience's deeply engagement to the performance event formulate a challenge to the dramatists as they have to present and presence themselves in theatre. (Abdullah, 2017: 111)

The main interest of the theory of trauma at present has primarily emerged from different studies conducted on the effects of Holocaust and its repercussions. This theory is also applicable and valuable for the field of literary analysis and cultural studies. Regarded as a masterpiece in trauma studies, Caruth's Unclaimed Experience: Trauma, Narrative and History (1996) provides a theatrical perspective in exposing the traumatic effects of war and violence along with other studies. In the present work, Antonin Artaud's Theatre of Cruelty is utilised to explain the issue of staging violence and what Artaud calls the "concrete language of the stage". Accordingly, this paper aims to see how dramatists have adequately presented new understanding of the role of theatre in viewing a community that experiences a continuous trauma caused by war, turmoil, displacement and loss.

\section{2-Trauma: an overview}

The term 'trauma' originated from the ancient Greek word meaning a physical 'wound' (Sarat and Kearns, 2002). The meaning of the word has been expanded 
to refer to one's psyche as 'a violent shock'. Thus, the old Greek implication of the word 'trauma' is transformed from an injury caused by a physical act of violence on an individual, which can be healed, to a symbolic wound to an individual's psyche. Afterwards, the meaning of the concept of trauma was modified to refer to the cultural experience of an entire nation subjected to disasters and crisis, whether natural or not, such as that of armed or political crisis. Therefore, in a modern context, "trauma can be seen at once as a sociopolitical event, a psychophysiological process, a physical and emotional experience and a narrative theme in the explanations of individual and social suffering" (Kirmayer, Lemelson, \& Barad, 2007: 1). Therefore, in modern times, 'trauma' as a concept has departed from its classical ground and become increasingly prevalent in other fields of studies, such as literature, psychology and culture. Moreover, it has become a complex term that is connected to the mind, soul and identity, which cannot be easily healed as a physical wound. In this regard, Freud asserts that "the wound of the mind-the breach in the mind's experience of time, self and the world - is not, like the wound of the body, a simple and healable event" but rather an event that "is experienced too soon, too unexpectedly, to be fully known and is therefore not available to consciousness until it imposes itself again, repeatedly, in the nightmares and repetitive actions of the survivors" (Caruth, 1996:3-4).

Judith Herman (1997) vividly elucidates the distinctiveness of traumatic experiences. In her psychological approach to the concept of trauma, Herman aptly explains how traumatic events have a power to overcome and affect people's daily life. She stresses further that traumatic events undermine individuals and arouse negative feelings of being paralysed for those who are unable to handle an experience, thereby intensifying their hatred for a life that has become nothing but a vacuum and entirely meaninglessness. Hence, traumatised people arrive at a conclusion that they are also humiliated by others and will never be the same, as Herman points out:

Traumatic events call into question basic human relationships. They breach attachments of family, friendship, love and community. They shatter the construction of self that is formed and sustained in relation to others. They undermine the belief systems that give meaning to human experience. They violate the victim's faith in a natural or divine order and cast the victim into a state of existential crisis. (Herman, 1977:151)

Caruth (1996) identifies three essential characteristics of trauma, namely, "belatedness" or the temporal gap between knowing and not knowing, "physical or external violence" that damages the psyche and "repetition of past traumatic events'. In its general definition, trauma is defined as "an overwhelming experience of sudden or catastrophic events, in which the response to the event occurs in the often delayed, uncontrolled repetitive appearance of hallucinations and other intrusive phenomena" (11). This "overwhelming experience" implies that "the victim's brain [is] not prepared for a shattering experience. The victim [is] not ready to feel pain and anxiety" (LaCapra, 2001: 90). Consequently, a 
reaction to trauma is delayed and disturbed; it disrupts the victims' ability to live in the present life, haunting the survivors through the form of dreams, nightmares and flashbacks and rupturing the integration of the consciousness and unconsciousness. Similarly, Erikson states that to be traumatised precisely means that "something alien breaks in on you, smashing through whatever barriers your mind has set up as a line of defence" (1995:183).

Caruth (1996) emphasizes that living with psychological wounds emanating from unresolved traumatic experiences can affect and disturb individuals to an ostensibly intolerable degree of isolation. Therefore, the act of surviving trauma involves and opens up new modes and ways of understanding the experiences of relating and being related to others. Accordingly, a crucial point involves envisaging the effect of trauma and creating an important contribution to the ways of understanding and reconstructing the historical, political and ethical events, thereby permitting a further dimension where immediate understanding is unattainable. Moreover, Caruth believes that as a special form of memory, addressing trauma gives voice to the survivors retelling their ordeals to others and consequently preserving their memory, forcing them to search and reconstruct their own identities. She adds:

The meaning of trauma's address beyond itself concerns, indeed, not only individual isolation but a wider historical isolation that, in our time, is communicated on the level of our cultures... . A speaking and a listening from the site of trauma - does not rely I would suggest, on what we simply know of each but on what we don't, yet know of our own traumatic pasts... In a catastrophic age, that is, trauma itself may provide the very link between cultures: not as a simple understanding of the pasts of others but rather, within the traumas of contemporary history, as our ability to listen through the departures we have all taken from ourselves. (1995:11)

Recently, scholars of trauma studies, including Caruth, Felman, LaCapra and Vickroy, have stated that literary approaches to trauma provide essential dimensions to historical and psychological studies. Moreover, they "raise important questions about the possibility of verbalising the unspeakable, narrating the unnarratable and making sense of the incomprehensible" (Schönfelder, 2013: 30). Paradoxically speaking, literary trauma writing involves an attempt to delve into and communicate the 'denied, the repressed and the forgotten' wounds caused by tragedies. Hartman (1995) believes that "the literary verbalisation, however, still remains a basis for making the wound perceivable and the silence audible" (259).

Therefore, the goal of trauma literature, as Vickroy (2002: 29) asserts, is not only to clarify or present a traumatic experience through a narrative process but also to perform trauma as a means of "witnessing or testifying for the history and experience of historically marginalised people". Caruth (1996) argues that literature verbalises terrifying experiences through a 'gap in understanding' that involves silence, repeated breakdown of language and failure of understanding; 
thus, literature is an ideal realm for performing traumatic experiences and its incomprehensibility. Moreover, she discusses language strategies for the literary representation of trauma, which suggests the interference of literary language and psychoanalysis as "interested in the complex relation between knowing and not knowing" where "the language of literature and psychoanalytic theory of traumatic experience precisely meet" (1996: 3). Analysing literary texts via the theory of trauma can shed "a light on figurative or poetic language and perhaps symbolic process in general, as something other than an enhanced imaging or vicarious repetition of a prior (non)experience" (Hartman, 1995: 540). Consequently, literary language provides a free ground across boundaries to search for memories, inner reflections, recollections, foreshadowing, flashbacks and alien experiences. These factors are stamped by tragedies, sufferings, wounds and traumas, which are personal and collective. Trauma and its consequences have become interesting topics for theatrical art and sources of artistic inspirations due to the vividness and the disturbing disposition of traumatic experiences. As an overwhelming and effective force that proves to be incapable of grasping data cognitively and consciously, Caruth's definition of trauma can be traced back to Artaud and his Theatre of Cruelty. Artaud supports Caruth in her belief that the information thrown into the unconscious mind has a considerable influence on the overall conscious awareness.

The present paper shows that in writing about their collective pasts and their ongoing sufferings in a torn and wounded country, Al-Assadi and Ghazi strive to portray characters who have faced and handled continuous years of traumatic events of war, violence, struggle and displacement through literal and figurative language and formidable images.

\section{3-Artaud's theatre of cruelty}

Enigmatic images revealed by traumatic memories may have the same features of a 'plague' as presented by Antonio Artaud in his book The Theatre and Its Double: "The plague takes dormant images, latent disorder and suddenly carries them to the point of the most extreme gestures. Theatre also takes gestures and develops them to the limit. Just like the plague, it reforges the links between what does and does not exist in material nature" (1970:18). Similarly, staging the traumatic images can work effectively on the audience's senses and drive them to feel the suffering of the characters because they are familiar with a type of trauma, whether personal or cultural. Artaud claimed that the traumatic image 'upsets our sensual tranquillity, releases our repressed subconscious and drives us to a kind of potential rebellion' (Artaud, 1970:19).

Moreover, Artaud advocates that theatrical performance is the only solution for a society to rebel against malaises, violence and dominance. 'The theatre must make itself the equal of ...liberated life which sweeps away human individuality and in which man is only a reflection,' Jannarone writes (2010:107). Artaud's provocative Theatre of Cruelty is based on psychological theory (particularly, Freud's three divisions of human psyche) and on destroying all the barriers between actors and audiences to involve the latter into the events in the play 
unconsciously. Artaud considered mental cruelty as a means to achieve freedom and peace. In this context, Artaud believes that audience must be placed under immense emotional pressure through which they reveal their animalistic, unconscious, ambiguous, dangerous and inexplicable desires. In this stage, visual and auditory effects (such as breathing, animal sounds, unrestrained gestures, colossal masks and strange puppets) are largely used, thus, allowing the audience to transcend their sensual and conscious world and recognise the unconscious. Consequently, narrowing the space between the narrative world and the real world offers people a chance to face their dark side and purify their psyche.

As a living organism, memory is shaped by past experiences and new interpretations of these experiences, which might be different from the first time people encountered them. Literature shows how a traumatic experience can shape and "force us to rethink our notions of experience, and of communication" (Caruth, 1995:4). However, the relationship between theatre and memory is intricate and multifaceted. Theatre is considered a compatible medium for memory, although the presentation of a theatrical performance seems to be in conflict with the memory. However, this argument does not indicate that theatre is an archival medium; rather, it indicates the falsehood of the powerful dominant systems of modern civilisation, history and reality. Different from other genres, drama comprises an active participation of flesh-and-blood human communication on the stages of life. The characters in the selected plays interpret and revise their traumatic past in the magical and metaphysical theatre that "shatters the solitude of the self and brings communion and personal metamorphosis" (Esslin, 1976: 171).

\section{4-Trapped in a battle zone: Al-Assadi's Baghdadi Bath}

Al-Assadi's Baghdadi Bath (2005) portrays life in Iraq before and after the US invasion in 2003 through two Iraqi bus drivers, Hamiid and Majiid, who are brothers and are struggling to survive in a chaotic country. The two characters stop to have a Turkish-style bath on their way to Baghdad coming from Amman. They carry the corpse of a politician who nominated himself for the election and was killed on the borders between Jordan and Iraq.

In Artaudian theatrical devices of movement, sound, setting and articulated and unarticulated language, Hamiid and Majiid strive to understand the violence that pervades their collective past and present traumatic experiences and continue to intimidate their future. Through the two characters, Al-Assadi staged cruelties, such as verbal violence, murder, prostitution and carelessness in a dramatic narrative form to expose the real truth of the atrocities hidden during the previous regime of Saddam Hussein and the corrupted life caused by the occupation with all its repercussions on Iraqi public life. Moreover, the roles played by the characters highlight the state of contradiction in Iraq. Majiid, the elder brother, is ready to sell himself to the 'devil' in an attempt to escape poverty and marginalisation. He considers the US troops as saviours, justifying his action with a pragmatic speech that reflects a complex personality; he says, 'we must take advantage of the present situation to make up of our losses' (Baghdadi Bath: 118). 
He hates the invaders but finds no embarrassment in cooperating with them. In a conversation with his brother, Majiid talks about his unfulfilled dreams of learning and of being a famous singer and how he now becomes a prisoner of pleasure and women. He abandons his family to a point that he does not attend the funeral of his father. He says to his brother that he has a nightmare where he "saw [his] father cut off and thrown into the tub" (Baghdadi Bath: 115). Majiid seems "overwhelmed with guilt" for neglecting his father and then his mother and chasing only his own interest. He is aggressive towards others, particularly his younger brother Hamiid, and uses violent and obscene language throughout the play.

In contrast to Majiid, Hamiid (the younger brother) is against Saddam's regime and the US invasion. In a moment of revelation, Hamiid bitterly recollects a traumatic past experience that has been rooted inside his soul, causing a spiritual scar that he cannot forget. This experience torments him, and he suffers from post-traumatic stress disorder (PTSD). He is denounced to live a daily routine that coexists with the detestable re-enactment of the traumatic event. Under Saddam's regime, Hamiid was forced to drive a group of political prisoners to mass shooting and then send their corpses to mass graves. In sordid detail, Hamiid describes the traumatic experience of execution that haunts him:

They made the prisoners get out [of the bus], stand in random order, and then suddenly they started shooting. The prisoners fell without saying a word. The air was engulfed in a horrible silence. I was overwhelmed with fear... with filth... They didn't even bother to bury these men where they'd murdered them. They wanted to desecrate them even further, so they carried them with blood dripping from their bodies into the bus. They ordered me to drive somewhere else... I wanted to puke. The bus reeked of blood. They ceremoniously and joyfully carried the corpses out of the bus and threw them in a ditch... The officer in charge came to me and ordered me to clean the bus and wipe away all traces of blood... They turned me into a mop they used to clean up their crimes. I got sick. I puked blood. (Baghdadi Bath: 124)

Hamiid relives this traumatic experience through flashbacks, nightmares and terror, which reflect belatedness and latency as symptoms of PTSD. According to Caruth (1995), traumatic influence is sometimes not evident at the same moment of an event; rather, it intrudes upon the victim unexpectedly after the traumatic event has occurred, thereby haunting the victim until it controls his narrative memory. Caruth (1995) further illustrates how, "the attempt to gain access to a traumatic history [...] can only be perceived in inassimilable forms" (156). In this sense, Al-Assadi plays with language symbolically. Baghdadi Bath presents an attempt to access the victims' traumatised psyche, which, symbolically speaking, portrays a fragmented situation that examines the maze of an Iraqi and a dilemma faced by a deep-rooted civilisation. 
Felman and Laub (1992) suggest that a survivor feels that the traumatic event is endless and "continues into the present and is current in every respect" (69). Hamiid's traumatic experience, although real, "took place outside the parameters of 'normal' reality, such as causality, sequence, place and time'. He continually expresses the painful and terrible reality of Iraqi life as he says, 'Good morning explosions... Good morning, corpses lying on the pavement" (Baghdadi Bath: 120). For Hamiid, the actual tragedy is that the effects of past experiences cause a change in his soul where the event intrusively returns to him. Moreover, the humiliation, disasters, cruelty and violence of the world incarnated in Iraq particularly after the invasion, are forcing him to re-experience the past event. Furthermore, the shocking and horrifying intrinsic cruelty and its appearance in life leave an ethical question unanswered. The author of the play suggests no solution to the cruelty and violence that pervade Iraqis' lives. Al-Assadi probed into the cruelty inherited in the human psyche as he attempted to disturb the peace of those who do not show any concern towards Iraqis as the play is enacted in Arab and European countries. He theatrically attempted to expose the lies, meaninglessness and double standards of life.

The second scene of the play takes place at the border between Amman and Baghdad. The second scene concentrates on the corruption of the political elections in Iraq. To shock the audience and involve them in the events of the play, the second scene becomes a direct assault on human emotions. It portrays how the Iraqi citizens are inflicted by humiliation everywhere at the border and how corpses are desecrated. Furthermore, the second scene echoes Artaud's view of the world as meaningless and absurd, which reflects the terrible reality of existence that human beings must face. In this sense, Hamiid describes the pointless absurdity of the political candidate's life and, symbolically, the life of the Iraqis:

He was just fine at the Jordanian border. He put a cigar in his mouth, gel in his hair and cologne on his neck. He was dreaming of winning the election. He kissed his mistress, put his arm around her, and suddenly she screamed. His head exploded... He fell in front of her like a handful of dust. It would've been better if he'd died on the Jordanian side. But as soon as we crossed the border his head exploded. (Baghdadi Bath:119)

For materialistic gain, Majiid insists on transporting the corpse of a political candidate from Amman to Baghdad. However, the brothers have to convince and humiliate themselves in front of the US forces controlling the border to be allowed to cross the borders with the 'prestigious body'. Hamiid abhors the idea, knowing that the Americans will desecrate the corpse and will ask to strip it. Being trapped in the war zone, Majiid has no other choice but to bury the remains in the earth, which the American soldiers force him to dig later. In the third scene, Al-Assadi, through Majiid's character, creates a disturbing image, with theatrical effects that play a profound role. The sounds of the explosions in the theatre bring the audience closer to the spirit of the play, such that the place, platform and stage 
become a tangled net of optical, acoustic and performative theatrical rituals that aim to shock the audience. To address his brother, Majiid painfully explains how he was tortured at the hands of American soldiers after his two attempts to transport the corpse of the candidate:

The only thing I could think of was to bury the corpse right there. I dug with my hands and fingernails. I dug and dug and dug. The rabid dogs came closer to the bus. I carried the pieces of the corpse out of the bus and threw them in the hole and covered them... covered them with dust. It was so vile and horrible. I wished for a moment I was dead. I hated myself. I cried so hard. It was midnight. I sat by the grave and realised I was all alone. I couldn't think of anyone but mother. I thought, would she forgive me if I asked her to? I wanted to erase all my mistakes and wash my sins away in front of her... For three days and three nights the tanks passed in front of me and circled around me... Soldiers passed in front of me without speaking... They wouldn't let me move... I didn't know what to do, Hamoud. I told them the truth. They told me to dig him up. I dug and dug with my hands... with my fingernails. I held up his feet... his head... his hands. They started to laugh. They aimed their guns at me... Then they pushed me into the grave and covered me with dust. And then... they disappeared. (Baghdadi Bath: 123)

The play ends where it started - in the bathroom, which symbolises a cleansing and clearing of the characters, particularly Hamiid, from spiritual blindness to eventually reach a realization. Then, the two characters gradually disappear from the stage, leaving only an engulfing steam covering the entire stage, which is transferred to the audience symbolizing the fogginess or lack of clarity in Iraq. Moreover, the steam signifies a barrier between the past with all its events and scenes of beautiful and sad moments and the blurry situation facing the characters and Iraqis in general. Particularly, it expresses the intellectual conflict between the past and the present. The play is an attempt to cast some light in the dark areas of the Iraqi human soul, which is torn between nostalgia (an involvement in a state that has no relation to its cultural history) and its drift towards an unknown or blurred future.

\section{5-Audible silence: Breaking the barriers in Gazi's A Feminine Solo}

In Gazi's play A Feminine Solo, two Iraqi women of different ages, Noor and Hayat, break all "boundaries of time and place, of self and subjectivity" (Felman and Laub, 1992: 58) that dominate them in a restricted patriarchal and violent society. The play focuses on traumatised and marginalised women who have suffered from social injustices, religious extremism (Noor) and prostitution (Hayat). Noor is a victim of a painful traumatising event, whose details live inside of her at every moment. Her traumatic memory began under to the old regime of Saddam Hussein. During that regime, if a person is accused of joining a political 
or religious party, particularly the Islamic party, then all the members of his family will be humiliated. Accordingly, because Noor's brother was accused of being a member of an Islamic party, their entire family experienced tragedy. Her father was killed, and her mother passed away mourning her son and her daughter. Noor who was captured by the members of Ba'ath Party was severely tortured, abused and raped by the members of Ba'athist regime. Painfully, she reveals what she experienced in the prison:

Noor: ...I was in a room without lineaments... or window or door. I didn't see anything. I just heard screaming, weeping of women and crying of a child over his mother that's poisonously killed... and that who is begging them or swearing and... (as if someone has slapped her unexpectedly) What have I to take off? ...My clothes? Please cover me up, brother. I am just like your sister... (a fist on her belly made her fall down) Oh... Oh... Please officer, you accused me of joining a religious party, not a PROSTITUTION... (screaming)...

As a victim, Noor's loss and conflict impose a heavy burden that made her live in the shadow of her deceased family. She turned her house into an eternal cemetery, preoccupied by and celebrating death as her only comforts. Hence, the memory of her traumatic experience is vital in explaining her deep psychic pain. Felman and Laub (1992: 69) state that the victim of a traumatic experience cannot recuperate from it when "trauma survivors live not with memories of the past, but with an event that could not and did not proceed through its completion, has no ending, attained no closure and therefore, as far as its survivors are concerned, continues into the present and is current in every respect". Being a bereaved person who is immersed in all details of her trauma, Noor has lost connections with other human beings and lost her integrated identity. She alienates herself from others, thinking that people are only a source of danger. From the beginning of the play, she shows her hatred towards the outside world and waits for any chance of retaliation, "[I wish to] live in a cave, I see no one and no one sees me".

Similarly, Hayat is another victimised and traumatised character. The play starts with Hayat knocking on Noor's house at night, asking for shelter because of the shooting outside. The pleas and terror that have befallen the place because of armed confrontations on the way force the dark, gloomy housekeeper (Noor) to host the suspicious alien (Hayat) with her thick blond hair and her body, which twists as if she were listening to an Oriental dance. As a prostitute and a dancer, Hayat is the opposite of Noor, who is a religious extremist. The first encounter between Noor and Hayat is a heated one. Noor does not allow Hayat to enter her house because she trusts no one at all. According to Herman (1997), the traumatised woman tends to withdraw from relationships; even when she is free, she likes to be isolated. However, Noor is forced to open the door and lets Hayat in because of her continuous knocking and begging. Hayat tries to start a conversation with Noor only to spend the night; however, Noor refuses and rudely tells her to leave immediately when the shooting stops. Hayat ignores her 
dismissal and continues her speech, asking Noor why her home "is so dim with no light or an open window", and she "feel[s] very terrified in darkness". Noor replies that "darkness is a veil for the woman". Noor, whose name ironically means light, finds her safety in darkness and in being invisible to others. Psychologically speaking, that might be attributed to the deep harm of the traumatic experience and her witness to the violence of the society that made her veil and cover her hidden and painful scars. Noor is still trapped in that old-new moment, which reflects what Smith (1994) portrays in his novel Only Forward, that is, when a drastic thing happens,

part of you is seared into place, and trapped for ever at that time. The rest of you moves onward, dealing with all the todays and tomorrows, but something, some part of you, is left behind. That part blocks the light, colours the rest of your life, but worse than that, it's alive. Trapped for ever at that moment, and alone in the dark, that part of you is still. (164)

Hayat seems full of life, as her name is a literal translation of the word 'life', trying to enjoy every moment, telling dirty jokes and using pun whenever she talks about men. Nonetheless, she reveals the story of her overwhelming experience of a catastrophic event. Hayat was married and had a baby boy. One day, terrorists drag her husband and son out of their house and kill them for their connection to another religious sect during the sectarian war in 2006. Suddenly, she faces a headwind, finding herself a vulnerable and lonely woman with no home, husband and son.

Hayat: Believe me I wasn't like this [a prostitute] ...I was pretty and a prudish woman, just like you... I married and my husband and I pray every night to achieve our dream of having a baby... the dream came true and we got a boy [a sound of ululating fills the stage] ...then in a very moonless night, all our dreams transformed into nightmares... men with red eyes like flames of fire and heads with no facial features, the black covered their faces and hearts... entered our house... I begged them a lot, kissed their hands, their shoes but in vain... They dragged them out into street... I was screaming, please for God's sake leave them, they have done nothing... Please, they are not criminals. They didn't listen to me or to my screams... they killed them. And the only reason is that they have different religious sect...

In such political disorder and patriarchy, Hayat is abused by a man who offered her help to leave the country. Then, she discovers that this man was a procurer, who has sold her for prostitution. Desperately, she becomes a subject to sexual abuse, which ironically becomes her only way to earn her living that eventually collapses into disillusionment. Every man she meets wants to violate and abuse her body. Her state as a prostitute has been solidified in the patriarchal community who considers her as a moral and social malady that has to be condemned and negatively judged by religious values. By contrast, Noor 
attributes the illness and corruption of the society to impurity and $\sin$ as represented by women like Hayat:

Noor [holding a rag and cleaning under Hayat's foot]: You and those who are like you are the reasons behind God's curse. All of what happens to us is because of your bad deeds and sins.

Hayat [treading on the rag and preventing Noor from continuing to clean]: Stop, stop it. Who are you to decide who is deemed to Heaven and who is deemed to Hell? ...I am a human just like you, and it is only God who can punish or reward, it is not YOU! [She reads from the Qur'an] 'It is $\mathrm{He}$ who forgives and who torments; $\mathrm{He}$ is The Ultimate Forgiving and Merciful'.

Noor's and Hayat's traumatic memories are manifested by excessive images and bodily sensations. Their memories do not follow a clear chronological narrative. According to Caruth, both the characters face the repetition of compulsion and created memories, which return as nightmares and flashbacks. In line with this argument, Meek (2011: 5) stresses that experiencing a trauma, whether physical or psychological, "can cause individuals to suffer behavioural and memory disorders over extended periods of time". However, remembering and retelling their terrible experiences to one another are considered prerequisites for healing and are part of the society: "They realise that they can live together if they choose to recognise each other. At the same time, what demarcates Hayat's honour is her perception that we all need another chance to be understood. She asserts that the only way to live together is to tolerate difference and nonconformity and accept each other," writes Abdelhameed (2016: 6).

A Feminine Solo concentrates on delineating the inner life of Noor and Hayat's repressed and subconscious fears and manias. In non-superficial realistic techniques, playwright Gazi, similar to Artaud, revealed the true nature of human beings and their irrationality, violence and chaos. He theatrically portrayed the inner and restrained life of these women by applying theatrical techniques that appealed directly to the audience's nerves and senses. The stage becomes a reflection of the inner selves of the characters with only a wall, a rusted iron door, large iron rosary beads, chains and locks clutching the handle of the windows and hanging from the ceiling and an iron sofa. Everything on the stage is rusted, mirroring the women's lives, which are turned into a rusted and dead object by their traumatic experiences. In addition, the playwright designed the stage with no barriers between the actresses and the audience whose repressions are involved as they sit surrounding the show in a small circle.

Noor and Hayat encounter a conflict between conveying the terrible events and denying them. Nevertheless, the act of retelling their traumatic experience, visually and narratively, is an important step in disentangling the entrapment of traumatic reality and its repercussions. After the revelation of their traumatic experiences, Noor and Hayat can now understand their overwhelming intrusive 
emotions and distorted memories, and they can overcome their fear. In the introduction of her book Trauma and Recovery, Herman describes eloquently this change of attitude as follows:

The conflict between the will to deny horrible events and the will to proclaim them aloud is the central dialectic of psychological trauma. People who have survived atrocities often tell their stories in a highly emotional, contradictory, and fragmented manner which undermines their credibility and thereby serves the twin imperatives of truthtelling and secrecy. When the truth is finally recognised, survivors can begin their recovery. But far too often secrecy prevails, and the story of the traumatic event surfaces not as a verbal narrative but as a symptom. (1992: 1)

Noor and Hayat have different ethical standards and different perspectives towards religion, men and life, which are illustrated as follows:

Noor [brutally takes the prayer cloth from Hayat as if mad]:

But I am not like YOU... Do you understand? Not like YOU... Take off my PRAYER CLOTH... take it off [madly takes it off]. Do you believe, yourself, that you are a believer? Rubbish... rubbish, all of you are rubbish. The prayer cloth is a sign of religious authority, it is swapped between the characters and the one with the prayer cloth listens and she has the authority to judge. The key point is that they swap.

Hayat: Poor creature, you are still in the prison, you don't want to leave it. The prison was dark, dreary, and your house is just like the prison. Get out of it, look at people outside. There may be thousands of men and women who need your help and you can offer your help, and I may be one of them. Believe me, the path to Heaven is full of people, sun and warmth.

Nevertheless, Noor and Hayat find a meeting point as they share the same agony and loss in a moment where the play becomes a place to launch political messages: Hayat: "What we got from change... transparency, democracy... and the unity and text of shaking fragile bodies". Then, Noor says, "Hand in hand, no weapon in hand, no militias in the rule of law... Ok who is the killer then??

A Feminine Solo ends tragically. A sniper kills Hayat when she opens the door at dawn en route to bring breakfast. However, through visual and narrative images, the play reveals a message that violence, sectarian war and other social and political negative phenomena lead nowhere. The play concludes that Iraqis, particularly women, despite their predicament and ordeal, will never shut down the window of hope. Rather, they will allow sunlight to penetrate the windows that have not seen light for years and insist on continuing with life in the bright light away from the prevailing darkness. This play is also a call for raising awareness that Iraqis seriously need a sense of compassion and humanity and understanding, regardless of their religious sect, ethnicity or political faction. 


\section{6-Conclusion}

Through the prisms of trauma theory and Artaudian Theatre of Cruelty, AlAssadi's Baghdadi Bath and Gazi's A Feminine Solo bear witness to the drastic and shattering traumatic effect of the war in Iraq and protest against the chaos, disorder and political upheavals that usurp Iraqis past and their present and make their future unpredictable. Moreover, the selected plays present a bleak portrait of Iraq as a landscape of war where people have been greatly suffering the loss of human spirit and living an ongoing trauma on personal and collective levels.

Shaped by those traumatising experiences, the playwrights conceive trauma as an absolute prerequisite to living in Iraq. However, their plays offer new hope to the victims and traumatised survivors by transforming the stage to a plea and witnessing of Iraqi agony and calamities.

Al-Assadi's Baghdadi Bath transports its audience to the core of the hell that pervades Iraqi life before and after the US invasion through its two male characters, Majiid and Hamiid. Through the brothers' narration and stage violent actions, the playwright takes the audience to the horrible nightmares and the grey zone that the brothers find themselves trapped, facing physical and spiritual death at every moment. The two characters are victims of violence and witnesses to their country's catastrophic existence.

Similarly, Gazi's A Feminine Solo expresses the ongoing traumatisation of two women, Hayat and Noor, whose idealised lives suddenly have fallen into a distorted fantasy realm because of the atrocities they have encountered. After losing their own family members and being raped and tortured physically and psychologically, Noor and Hayat demonstrate how a traumatic experience disrupts the sense of integration between the self and others. Unlike Majiid and Hamiid in Baghdadi Bath, the women in Gazi's A Feminine Solo can overcome the fear of their traumatic memories by revealing and understanding their overwhelming emotions and memories, thereby deciding to open the door and window and letting the light enter to defeat the darkness that has permeated their souls and their country.

\section{Endnotes}

i. The Arabic script of Feminine Solo was sent by the dramatist Mithal Gazi in 2017. Therefore, no page number is mentioned. (See Hadeel Abdelhameed, 'Memory and Emotions: Female Characters in Iraqi Theatre about War Humanities', 2016, 5, 75; doi:10.3390/h5030075 www.mdpi.com/journal/humanities.) 
Maysoon Taher Muhi (PhD)

Department of English-College of Education for Women

University of Baghdad

Email:maysootaher@gmail.com

\section{References}

Abdelhameed, Hadeel. (2016). 'Scripting Memory and Emotions: Female Characters in Iraqi Theatre about War'. Humanities, 5: 75. 1-7

Abdullah, Neval Nabil Mahmoud. (2017). 'Fragmented Psyches and Devastating Testimonies: Staging the Post- Traumatic Experience in Iraq through Heather Raffo's 'Nine Parts of Desire' and Judith Thompson's 'Palace of the End'. International Journal of Arabic-English Studies, 17:119-126

Al- Assadi, Jawad. (2008) Baghdadi Bath, trans. Robert Myers and Nada Saab. PAJ: A Journal of Performance and Art 89: 112-23.

Artaud, Antonin. (1970). The Theatre and Its Double: Essays. Montreuil: Calder.

Caruth, Cathy. (1995). Trauma: Explorations in Memory. Baltimore: Johns Hopkins University Press.

Caruth, Cathy. (1996). Unclaimed Experience: Trauma, Narrative and History. Johns Hopkins University Press.

Erikson, Kai. (1995). Notes on Trauma and Community. In Caruth, Cathy, (Ed.). Trauma: Explorations in Memory. Baltimore: Johns Hopkins University press.

Esslin, Martin. (1976). Antonin Artaud. New York: Penguin.

Felman, Shoshana. (2002). The Juridical Unconscious: Trials and Traumas in the Twentieth Century. Cambridge, MA: Harvard UP.

Hartman, Geoffrey H. (1995). On Traumatic Knowledge and Literary Studies. New Literary History 26 (3): 537-563.

Herman, Judith. (1997). Trauma and Recovery: The Aftermath of Violencefrom Domestic Abuse to Political Terror. New York: Basic Books.

Jannarone, Kimberly. (2010). Artaud and His Doubles. Ann Arbor: The University of Michigan Press.

Jay, Martin. (2003). Refractions of Violence. New York: Routledge.

Kirmayer, Laurence J, Lemelson, Robert, \& Barad, Mark. (2007).

Understanding Trauma: Integrating Biological, Clinical, and Cultural

Perspectives. New York: Cambridge University Press.

LaCapra, Dominick. (2001). Writing History, Writing Trauma. Baltimore: Johns. 
Laub, Dori. (1992). Bearing Witness, or the Vicissitudes of Listening. In Shoshana Felman and Dori Laub. (Ed.). Testimony: Crisis of Witnessing in Literature, Psychoanalysis, and History. New York: Routledge.

Sarat, Austin \& Kearns, Thomas R. (2002). History, Memory and the Law. Ann Arbor: University of Michigan.

Schönfelder, Christa. (2013). Wounds and Words: Childhood and Family Trauma in Romantic and Postmodern Fiction. Bielefeld: Transcript Majuskel Medienproduktion GmbH.

Smith, Michael Marshall. (2010). Only Forward. UK: Harper Collins Publishers.

Vickroy, Laurie. (2002). Trauma and Survival in Contemporary Fiction. Charlottesville: University of Virginia Press 